\title{
IMPROVING TRANSPARENCY THROUGH E-GOVERNANCE
}

\author{
Mysore Ramaswamy, Southern University, Baton Rouge, LA, mysore@acm.org
}

\begin{abstract}
One of the ways to achieve transparency and combat corruption is by automating government to citizen interactions. The process of automating these interactions using information and communication technologies (ICTs) needs to be analyzed as a socio-technical information processing system. During the process of improving the enforcement of rules via automation, socio-cultural factors need to be considered as they play a very important role. Automating existing bureaucratic processes that are defective will not yield results. Improving the enforcement of rules is clearly the best way to combat corruption. The introduction of e-Government can play a major role in this context as it automates several processes. Without some method of categorization, assessment and modification of existing administrative processes, the formation of good policy and planning capable of leveraging the current capacity of institutions to deliver public service in a more transparent and efficient way is simply not feasible. In this paper, we propose a methodology to render transparency in governance using information and communication technologies that goes beyond mere automating existing citizen-government interactions.
\end{abstract}

Keywords: e-Government, Information and Communication Technology (ICT), Process Restructuring, Public Sector Corruption, Transparency Perception Index.

\section{INTRODUCTION}

Recent innovations in information and communication technology (ICT) have given hope to the idea that new technologies in the form of e-government systems can be used to combat corruption in the public sector. Most governments across the world desire their citizens and businesses to interface with them through electronic means for the obvious reasons of efficiency in cost-saving and effectiveness. However, whether the transparency in process and information-sharing that this presupposes is also an equally important social and cultural objective for all leaders is a less obvious assertion. As Jane Fountain states in her work, there is a certain element of the 'perversity of incentives' to acknowledge here; Kedzie calls this the "Dictator's Dilemma" in the state $[1,7]-$ where increased efficiency and political efficacy (brought about by ICTs) are positively related to each other, and negatively related to authoritarian and highly centralized control.

This is especially true in developing countries where the newly emerging bureaucracies are hesitant to give way to automated systems [18]. These technologies can serve a variety of different ends: better delivery of government services to citizens, improved interactions with business and industry, citizen empowerment through access to information, or more efficient government management. The resulting benefits can be less corruption, increased transparency, greater convenience, revenue growth, and/or cost reductions. Analogous to e-commerce, which allows businesses to transact with each other more efficiently (B2B) and brings customers closer to businesses (B2C), egovernment aims to make the interaction between government and citizens (G2C), government and business enterprises (G2B), and inter-agency relationships (G2G) more friendly, convenient, transparent, and inexpensive.

The term 'e-government' refers to the application of Information and Communication Technology (ICT) by government agencies In this paper, we prefer to use the term "e-governance" in a broader sense to include a deeper understanding of the way ICTs impact the existing (and potential future) interactions between a government and its constituents. In other words, e-governance goes beyond the 'what' of an e-government interaction that presumably delivers service to a constituent - and includes rather an analysis of the 'how' and 'why'. We note that one cannot improve upon something in automation that is not already rational and functional in current daily practice. The term 'transparency' is used in this paper to mean disclosure or openness regarding all transactions with public agencies. This is a necessary precursor for the eradication of corruption. 
This paper is organized as follows. First we analyze the barriers that must be overcome before e-government can be implemented. Need for transparency and accessibility and interactivity issues are discussed next. This is followed by an analysis of sociotechnical factors and a framework for improving transparency. Concluding remarks form the last section.

\section{BARRIERS TO CHANGE}

The need to have better transparency is not restricted to the Western countries. In fact, it is more urgently required in developing countries. In this section, we look at some of the barriers for achieving transparency by implementing egovernment in developing countries. Barriers to change are identified in the following four areas: Organizational Characteristics, Human Capacity, Financial Capacity, and Technical Infrastructure [19]. Organizational characteristics such as the existence of local information technology (IT) departments that address questions of automation and efficiency, and the existence of collaboration between IT and public relations (PR) departments which results in the availability of streamlined public information are vital to the transformation process. To a large extent this presumes that the realization of coherent public diplomacy is contingent upon a state's ability to build itself a back-end capable of effectuating its own communication systems. Data-intensive collaborations at some point involve the issue of data ownership [5,21]. Such issues in a fledgling bureaucracy can be a potential stumbling block especially in government to government $(\mathrm{G} 2 \mathrm{G})$ transactions. In the same way that intelligence agencies in the United States post 9/11 discovered the major flaws in the ability of their respective vast systems to dovetail and cooperate effectively, so too do the various branches of government and their respective ministries face a challenge of interoperability. In addition, it is important to determine whether there are any institutionalized means of process review or opportunities for constituents to address their grievances. By developing the infrastructure and capacity to provide local service and service delivery, e-government can become a mechanism for spurring community involvement and thus become a catalyst for direct political interaction and/or e-participation [9, 14]. Naturally, this may be viewed with skepticism by various parts of the bureaucracy. In the context of developing countries, this is further exacerbated by the subservience of bureaucracy to political authority and the 'strongmen' that are frequently its human face.

The human capacity component in an institution is critical to the ability and capacity of that institution to evolve. For the purposes of this analysis, this component can be used interchangeably with the notion of social capital even in the limited parameters of a single institution. Social capital refers to the 'stock' that is created when a group of departments or divisions develop the ability to work together and create linkages for mutually productive gain. Agents in a collaborative network, even within one institution, learn of new technologies, opportunities, challenges, and the outcome of transactions more quickly because of the density of interaction within the network [18]. Vertically organized networks tend toward characteristics that adversely affect this sort of 'mesh' learning about information processing capacity by virtue of a lack of density and 'flatness' in the nodes of the social networks that drives the political apparatus. This is an interesting point to consider because whereas, complexity in networks may traditionally be associated with building up a sclerosis of sorts in an institutional body in terms of its ability to act, it can be suggested that a lack of complexity in an overly simple hierarchical network structure can equally result in a lack of clear action and effectiveness.

The financial barrier also is a critical one to the emergence of innovation and institutional transformation. This is largely about the creation of incentives for people to innovate. As it stands, the average salaries in IT departments of ministries in developing countries are quite low compared to the comparable private sector jobs, and do not create an environment conducive to innovation [28]. The most critical element here is a lack of commitment from the top strategic and financial - to the objectives of institutional transformation [11]. The status quo suits the purposes of many.

Barriers posed by technical infrastructure refer to problems of depreciating equipment, lack of standardization and interoperability, an overall disregard for licenses, and an unwillingness to capitalize on telecommunication infrastructure even when it is present (i.e. as in the case of the purported 'dark' fiber running through most major government buildings). This creates an environment where change is not a priority, and where complacency becomes a rule. 


\section{Issues in Information Systems \\ Volume 15, Issue I, pp. 123-131, 2014}

In developing countries, the issues of sustainability and ownership are critical; there is a strong tendency for projects to dissolve or disappear completely after funding runs out, in part because ownership and commitment by government figureheads and organizations is not always successfully assumed [19]. Moving toward institutional transparency does not necessarily serve the purpose of those who do not suffer the institutional status quo. The extent to which e-government projects could facilitate political participation is a social phenomenon that must manifest itself in the physical realm before it can extend to the virtual realm. In other words, the social reality of a political culture characterized by "unpleasant" interactions with all levels of public administration can easily transcend the objectives of any IT effort to provide the opposite. To provide online functionality that typifies an advanced polity is to present a solution thirty steps ahead of society. The technology itself can "leapfrog" various steps and standards, but should not be geared to leaping over public perceptions of "what could work here" and "what could never work here." Every society has its own answer to the question of effective ICT adoption, and in the case of developing countries, workable solutions are often hybrid; combinations of automation and social networking.

\section{NEED FOR TRANSPARENCY}

Corruption is the misuse of public power, office or authority for private benefit. This misuse manifests in many ways: bribery, extortion, influence peddling, nepotism, fraud, or speed money. Petty corruption is frequently found where public servants who may be grossly underpaid depend upon small kickbacks from the public to pad their pockets and feed their families. Grand corruption involves high officials who make decisions on large public contracts for their personal benefit, or to the benefit of organized, informal groups with highly aligned self-interest as the driver of their cohesion.

In many parts of the world, a major part of the problem in dealing with public sector or government bodies is corruption. No doubt, corruption has been around since time immemorial and indeed, may well be an engrained trait of human nature; nevertheless, most governments and technologists are interested in figuring out what means may be created to combat it. In this context, 'Panoptic Vision' as proposed by Heeks [17] affords a way to analyze this critical problem. The concept of Panoptic Vision is based on the construct that sees information technology (IT) as a key enabler of management control.

Public corruption can be largely attributed to government intervention in the economy. Therefore, policies aimed at liberalization, stabilization, deregulation, and privatization can sharply reduce the opportunities for corruption $[2,3]$. Where government regulations are pervasive, onerous or imprecise, and when government officials have discretion in applying them, individuals are often willing to offer bribes to officials to circumvent rules.

High levels of corruption are present where institutional mechanisms to combat corruption are weak or not used, and where a system of simple internal checks and balances does not exist. In such cases, entrenched political elite dominates and exploits economic opportunities, manipulating them in return for personal gains [12]. The significance and impact of corruption varies greatly across the world. Even though people may tolerate demands for small payments in return for official services such as the issuing of permits and licenses, they do not necessarily approve. They perceive it simply as the most painless, quick and workable way of obtaining things they want or need.

Typically, in a bureaucracy, discretion is structured by rules and standard operating procedures, and it does allow civil servants to take into consideration contextual variations and act according to other norms [20]. It has to be ensured that the uniquely human ability to act on broader societal norms is retained after ICT intervention in bureaucratic practices. The real challenge is to figure out how to modify practices that work in Western countries, so that they can work in transition/developing countries where there is no culture of accountability and transparency in any type of constituent-government interactions.

Cucciniello [10] describes a framework to monitor the degree of transparency based on four dimensions: institutional, political, financial, and service delivery. This model was designed to measure government transparency based on the information published on their institutional websites. The institutional dimension aims to capture the degree of transparency with regard to the government's mission and operations, its institutional activities and the 


\section{Issues in Information Systems \\ Volume 15, Issue I, pp. 123-131, 2014}

information it is obliged to publish by law. The political dimension aims to capture the degree of accessibility of information on political representatives, their political mandate and activities and other information, such as absenteeism at council meetings and salary. The financial dimension aims to assess the degree of transparency with regard to the use of financial resources, the solvability of governments and other financial issues. The service delivery dimension aims to assess the degree of transparency concerning the performance of governments in the delivery of services to citizens and businesses. Each dimension of the assessment framework is divided into different variables and assessed using specific measurements and checklists.

Each of the variables of the different dimensions is evaluated with reference to two factors: accessibility and interactivity. Three different types of information are relevant in this context: static information, dynamic information, and feedback information. Static information is information about the public agency and its mission, how it functions, and what it offers. This type of information does not change frequently and some of this information is required to be published in order to comply with existing regulations. Dynamic information consists of information about performance for each of the four dimensions stated above. Feedback information comprises performance-related feedback information.

E-Government Transparency Index [13] was developed in 2009 to address the following issues: a) Creating an accurate, actionable, and precise measurement of citizens' opinions on government transparency and b) Quantifying the relationships among online transparency, citizen satisfaction, trust, and the likelihood of participating and collaborating with government agencies. These indices are developed based on surveys conducted with randomly selected visitors to various government websites. Questions were asked about their experience with and perceptions of the different elements of the website. The objective is to gather information that answers the following questions: how thorough the information on the website is, how accessible it is, and how quickly it is made available.

\section{ACCESSIBILITY AND INTERACTIVITY ISSUES}

To ensure an effective strategy for e-government implementation, it is necessary that we analyze the accessibility issues as they exist today. In this section, we study the following two critical components that are essential for implementing e-government: digital infrastructure, and interaction content. Digital infrastructure refers to the mechanism through which users can access the cyberspace. Interaction content is what drives the users to go online. In the early stages, the Internet use relied on dial-up connections that offer limited capacity (56Kbps or less) and intermittent connectivity. The first generation of advanced services with continuous connectivity and expanded capacity (200Kbps to $1 \mathrm{Mbps}$ ) began to be deployed in the latter half of the 1990s. These include DSL services offered over telephone company copper wires, cable modem services offered over cable television facilities, and a small but growing number of wireless services (satellite and terrestrial). However, there are still significant portions of population who do not have access to these services.

Broadband Internet connectivity is viewed as an important part of the infrastructure required to ensure effective ecommerce. The Organization for Economic Cooperation and Development (OECD) states that the number of broadband subscribers in the United States is $16.8 \%$ (total subscribers: 49,391,060). The breakup is as follows: DSL: 6.5\%, Cable: $9.0 \%$, and Other: $1.3 \%$. United States ranks $12^{\text {th }}$ among the industrialized countries in the list of broadband subscribers per 100 inhabitants. By ensuring high-speed access and 'always-on' connections, broadband technologies substantially change the patterns of Internet usage [8]. Moreover, whether many of these services should even be classified as 'broadband' has been questioned. The Federal Communications Commission (FCC) defines 'advanced services' as capable of providing more than $200 \mathrm{Kbps}$ on both directions. By that definition, many cable and DSL systems do not qualify, as they are constrained to upstream bandwidths of $128 \mathrm{Kbps}$ or less. At a mere four times the bit rate, $200 \mathrm{Kbps}$ represents only an incremental step from a dial-up modem. Much higher capacity access networks offering services in the 10s to 100s of Mbps (or more) per household will be needed to fully unleash the full potential of advanced communications infrastructure.

Local governments have the following two important roles to play in the development of broadband infrastructure: (i) financier and (ii) infrastructure developer [1]. Financial incentives can be aimed at stimulating supply, demand, or both. Subsidies to commercial providers can be in the form of outright grants, low-cost loans, or tax incentives. Subsidies to users are typically temporary in nature, or targeted at disadvantaged groups. For example, LaGrange, 


\section{Issues in Information Systems \\ Volume 15, Issue I, pp. 123-131, 2014}

Georgia gave away WebTV equipment and service for a one year period in an attempt to get more of their socioeconomically citizens online [5]. Unfortunately, the attempt was largely unsuccessful, reflecting barriers to adoption that go beyond the cost of access, as well as unpopular limitations of the chosen technology - the WebTV devices used had no print capability. Broadband related subsidies appear to be more common at state and federal levels, where budgets are significantly large. For example, Pennsylvania administers a \$3.3million digital divide grant program based on federal funds from the Temporary Assistance to Needy Families (TANF) program. One of their grants was $\$ 457,000$ to the Glendale School District (located in economically disadvantaged area) to extend wireless broadband Internet access from one school to neighboring schools as well as citizens, and to give laptops to community members who partake of training opportunities [8].

The other strategy that local governments can pursue to stimulate broadband is to develop one or more aspects of the necessary infrastructure themselves. Based on an assessment of the communications needs and existing resources available to different groups of users, government can prioritize infrastructure developments for itself, local businesses, and citizens. A local government can deploy a network for its own needs, and later exploit any excess capacity to offer services to nearby businesses.

Wireless networks add their own complexity to the mix. Recently, Google while testing its first municipal Wi-Fi network in its hometown, Mountain View, Calif., using transmitters attached to street lamps, observed that people using Google's network could get online at home only by holding their laptops against a window. This was to be expected as using municipal Wi-Fi for residential coverage was "the equivalent of expecting street lamps to light everyone's homes."

The second critical component of e-society refers to the digital content that users can access User interactions with digital or electronic means have been grouped in a number of ways [11]. In the present analysis, it will be useful to categorize them in the following way: information services, communication services, and transaction services. A more inclusive e-society has to provide more useful digital interactions to a larger segment of the society, especially in the third category of transaction services.

In the context of e-inclusion, under the category of transaction services, government-to-citizen interactions of eGovernment become very significant. In order to build a more inclusive e-society, we need to address these questions:

- How can we make e-Government truly citizen-centric?

- Do we have objectives that are correct and realistic?

- How well are we achieving these objectives fully and cost effectively?

- Are these objectives jointly determined and agreed upon by the citizens and the government agencies?

We need better models of the processes used to plan, fund, develop, implement, operate, and evaluate successful eGovernment in various political and social, cultural, and economic contexts [1].

Although technology can create new or modified business practices at a rapid rate, successful adoption of new best practices must stand up to market forces. Technology and the marketplace are continually reshaping business activities and as a consequence, business strategies. An organization must continually work towards an alignment that fits into the organization's business strategy, IS strategy, ethical advancement and compliance strategies. This alignment should improve the likelihood that IS initiatives are explicitly linked to areas that are critical to successful business performance, provide a source of competitive advantage and ensure ethical compliance. The process of aligning strategies should heighten management's awareness and use of information systems to better support organizational goals, objectives, and ethical compliance. The role of IS should be that of a strategic enabler for competitive success, rather than just an operational supporter.

\section{SOCIO-TECHNICAL FACTORS}

Socio-technical factors pertain to exacerbated accountability dysfunctions that can occur as a consequence of automation [20]. According to Bovens [5] the major categories of dysfunctions are: Rule-obsession, Proceduralism, Rigidity, and Scapegoating. 
Rule-obsession or Output-obsession refers to the focus on outcomes over process. 'Proceduralism' refers to increased emphasis on procedures to avoid responsibility and accountability. Strict adherence to procedures cam render the bureaucracy to lose the ability to balance procedures with public values. Relying heavily on encoded computer procedures can undermine the effectiveness of public sector organizations.

The ability to take contextual variations into account is affected by the encoding of procedures which actually results in encoding rigidity. After developing a system, the embedded rigidity can make it difficult to modify as part of organizational learning. As a result of the introduction of ICTs in the public sector, there has been a displacement of accountability from bureaucrat to software engineer. When things go wrong, the tendency is to use the computer as a scapegoat. It is important to consider these socio-technical factors while building e-government systems in order that the citizens can have confidence in automated systems.

The degree of automation can vary across a wide range. Smith [30] states a scale of nine degrees of automation starting from the first level where the computer offers no assistance to the ninth level where the computer decides everything. In between these extremes, there are several levels where a varying degree human-computer interaction occurs. The appropriate level of ICT intervention depends on the particular interaction that has to be automated.

The need for transparency and accountability calls for automated systems. But in developing countries, where there is no culture of established bureaucracy, there is also a concomitant need for accommodating socio-cultural factors. An analysis of the existing bureaucratic practices in transition countries indicates two areas that need attention. The first pertains to the availability of information regarding governmental procedures to the general public. Acquiring such information is quite simple in most western societies. But in some developing countries government officials, especially at the lower levels, make it harder for the public to execute these transactions so their reliance on the officials who "sell" this information and "facilitate" the required transaction is not diminished. The roots of public sector corruption are found in such opportunities. The second area of concern is the convoluted way in which governmental procedures in general are laid out. In many countries, several layers of authority are embedded in the bureaucratic system. Efforts to build a congruous system to replace it have yet to emerge. This gives an opportunity for government officials to use the system to their advantage. Clearly, the simplification and clarification of procedures has not been their priority [19]. This elucidates the point that process restructuring should also accompany a concomitant improvement in the work and incentive conditions of the government employees delivering public service. This necessitates the emergence of an environment in which all participants have a share in the benefits of modern technology.

A critical component in the multilayered process of rendering transparency pertains to the availability of digital content that users can access. User interactions with digital or electronic means have been grouped in a number of ways $[11,16]$. In the present analysis, it will be useful to categorize them in the following way: information services, communication services, and transaction services. An inclusive and accountable bureaucracy has to provide more useful digital interactions to a larger segment of society, especially in the third category of transaction services [6, 7].

There is little apparent understanding as to where the main impact of ICTs will be, and this is manifested by an obvious collective misunderstanding as to what e-government should accomplish. The development of ICTs in government - to support both back-end and front-end systems - should come not only from the united front of a coordinated and coherent donor stream, but in conjunction with genuine efforts to promote organic (as opposed to transplanted) growth strategies [19]. Anything less will result in a continued flow of ineffective funding that misses the mark in terms of meeting the objectives of true institutional transformation, which in large part - and with few exceptions - describes the status quo in many developing countries today.

\section{A FRAMEWORK FOR IMPROVING TRANSPARENCY}

Clearly, ICT can play a critical role in bringing transparency in government to citizen (G2C) interactions. Automating existing bureaucratic procedures, per se, will not yield transparency. As Michael Hammer, a wellknown business consultant who championed business process reengineering, wrote an article in Harvard Business Review titled "Don't Automate, Obliterate." He stresses the importance of simplifying processes, eliminating non- 
value added tasks, and innovating to improve speed, quality, and service. No meaningful improvements can be expected by simply automating the existing inefficient processes. This is especially true for developing countries.

We propose a four-stage framework that will improve transparency by implementing e-government applications as indicated in Table 1. In the first stage, the existing procedures are viewed through the lens of Transparency Assessment Framework the details of which were stated an earlier section. At the end of this stage, we will have a set of critical processes that need intervention. In the second stage, we examine the selected processes from the view of socio-technical factors. At the end of this stage we will have processes that are free from Rule-obsession, Proceduralism, Rigidity, and Scapegoating. In the third stage, we restructure the processes to make interactions more efficient and effective. In the final stage, we automate the restructured processes.

Table 1. A Framework for Improving Transparency

\begin{tabular}{|l|l|l|l|}
\hline Stage I & Stage II & Stage III & Stage IV \\
\hline Current G2C interactions are & Selected interactions & Interactions are & Interactions are \\
Checked along the following & are made free from: & restructured to & automated with \\
dimensions: & $\bullet$ Rule-obsession & make them more & special emphasis \\
- Institutional & $\bullet$ Proceduralism & effective and & on accessibility \\
- Political & $\bullet$ Rigidity & efficient & and interactivity \\
- Financial & $\bullet$ Scapegoating & & \\
- Service Delivery & & & \\
\hline
\end{tabular}

In the first stage, existing government-constituent interactions are examined. The number of interactions is indeed very large as evidenced by the three stakeholder groups of constituents (citizen, business, and government). The gamut of interactions is also very diverse. The analysis is conducted along the four dimensions (institutional, political, financial, and service delivery) and the interactions are categorized based on the degree of perceived importance by the constituents. Socio-technical factors are considered in the second stage. Before manual procedures are automated, it has to be ensured that there are no problems such as rule-obsession and proceduralism. Not only will this help towards transparency, but it will also make acceptance by constituents easier,

Processes are restructured in the third stage. Automating legacy procedures that afforded plenty of opportunities for inefficiency and corruption will not yield results. The main objective of restructuring various processes before transforming them into digital interactions is to improve the effectiveness of bureaucracy as a system and make it more transparent. It is to be noted that placing an IT layer over and automating a faulty bureaucratic system may yield a more efficient system, but will certainly not be one desired by or responsive to its core constituents, and will not help in any way to combat corruption or perceptions of it. When automated processes result in disintermediation, it is necessary that the relevant entities are on board with new procedures. After completion of the restructuring stage, we are ready for implementing in the fourth and final stage.

This framework also provides a means of evaluating an extensive (if not comprehensive) series of governmentconstituent interactions. Depending upon the value of the parameters of the given transaction, we are able to make inferences on the potential of that transaction for potential of ICT intervention. This naturally opens up a wide arena of analysis, particularly for others who wish to specialize and focus specifically on the dynamics and characteristics of specific interactions where ICT intervention is useful.

\section{CONCLUSIONS}

The success of e-Government initiatives to improve transparency and combat public sector corruption will ultimately depend upon the acceptance of ICTs among its citizens. The basic building blocks of ICT implementation in public sector bureaucracy consist of digitized versions of interactions between the government and its constituents. In this paper, we have presented a framework that can identify and categorize dealings of the public with the different types of government structure. Restructuring the bureaucratic procedures and then automating 


\section{Issues in Information Systems}

Volume 15, Issue I, pp. 123-131, 2014

them in a systematic way as suggested in this paper affords a practical approach to render transparency and accountability to public sector. Measures such as e-Government Transparency Index will help in evaluating the

success of these measures. Future work in this area focuses on developing a comprehensive framework that will enable policy makers and researchers to point out the potential priority areas that need to be automated first to render accountability and transparency, and also yield a realistic estimate of resources needed to achieve such transformation. In addition, such an approach will also help in giving a better insight into process restructuring.

\section{REFERENCES}

1. Allison, Juliann Emmons. (2002) Technology, Development, and Democracy: International Conflict and Cooperation in the Information Age. Albany: State University of New York Press.

2. Al-Mashari, Majed, Zahir Irani, \& Mohamed Zairi. (2001). Business process reengineering: a survey of international experience. Business Process Management Journal, December 2001, pp. 437-455.

3. Alter, S. (2002) Information Systems: Foundations of E-Business. Prentice Hall, Upper Saddle River, NJ.

4. Berghel. Hal. (2005). The Two Sides of ROI. Return on Investment Vs. Risk of Incarceration. Communications of the ACM. 48.4. pp. 15-20.

5. Bovens, M. (2005) "Public Accountability," in Ferlie, E. J. Lawrence, E. Lynn, and C. Pollitt (eds.), The Oxford Handbook of Public Management, Oxford University Press, pp. 182-208.

6. Carbo, T. and Williams, J. (2004). Models and Metrics for Evaluating Local Electronic Government Systems and Services. The Electronic Journal of Electronic Government, Vol. 2, No. 1, pp. 99-106.

7. Carbo, T. and Williams, J. G. (2004). "Some Determinants of User Perceptions of Information Quality on the World Wide Web," Electronic Journal of e-Government, Vol. 2, No. 2 pp. 94-105.

8. Choi, S. et al. (1997). The Economics of Electronic Commerce, Macmillan Technical Publishing, Indianapolis.

9. Clark, K. and Baker, P. (2003). Municipal Advanced Telecommunication Infrastructure Project (MuniTIP). Georgia Center for Advanced Telecommunications Technology, OTP Policy Study No. 50103.http://www.gcatt.org/otp/papers/ MuniTIP.pdf

10. Cucciniello, Maria et al. (2012) "Assessing Transparency in Government: Rhetoric, Reality, and Desire," Proceedings of the $45^{\text {th }}$ Hawaii International Conference on Information Systems, (11 pages).

11. Fonseca-Lind, S et al (2008), Indirect Consequences of Sarbanes Oxley on IT Governance in Puerto Rico, IABPAD Proceedings, pp. 528-538.

12. Fountain, Jane E. (2001) Building the Virtual State: Information Technology and Institutional Change. Washington, DC: Brookings Institution Press.

13. Freed, Larry. (2011) Quantifying the Impact of Transparency. http://www.nrc.gov/publicinvolve/open/evaluating-progress/foresee-transparency-index.pdf

14. Government Technology. (2002). Pennsylvania Targets Digital Divide. http://www.govtech,net/news.news.phtml?docid=2002.1209.33355

15. Grimaila, Michael, R. Kulkarni, Abhijit, S. (2005). Challenges is Achieving Sarbanes-Oxley Compliance. The ISSA Journal. February, 2005.

16. Grimsley, M, Meehan, A, Sen Gupta, K (2006) Evaluative Design of e-Government Projects: A Public Value Perspective. Proceedings of the Twelfth Americas Conference on Information Systems, Acapulco, Mexico August $04^{\text {th }}-06^{\text {th }} 2006$.

17. Grimsley, M, Meehan, A, Tan, A, (2005) Capital Accounting: Evaluating e-Government projects from a community development perspective. Z. Irani, T. Elliman and O.D. Sarikas (Eds.) Proceedings of the eGovernment Workshop '05 (eGOV05), Brunel University, UK, 13th Sept. 2005. ISBN 1-902316-46-0

18. Heeks, R (2003). "Causes of eGovernment Success and Failure: Design Reality Gap Model," http://www.edevexchange.org/ eGov/ causegap.htm

19. Homburg, V. and Bekkers, V. (2002) "The Back-Office of E-Government," Proceedings of the $35^{\text {th }}$ Hawaii International Conference on Information Systems, (9 pages).

20. Keil, M. et al. (2003). Bridging the Digital Divide: The Story of the Free Internet Initiative in LaGrange, Georgia. Proceedings of the $36^{\text {th }}$ Hawaii International Conference on Information Systems, (10 pages). 
21. Koss, F. A. (2001). The Challenges of redressing the digital divide, Journal of International Affairs, 55 (1), 75-90.

22. Kuzmin, A. (2003). "The Two Dimensions of e-Government: Potential and Use," www.processconsulting.ru/doc/Two_dimensions_of_e-Government.pdf

23. Lee, H. et al (2003). The growth of broadband and electronic commerce in South Korea: Contributing factors, Information Society, 19 (5), 81-93.

24. Mason, S. M. et al (2003). Applying communication theory to digital divide research, IT and Society, 1 (5).

25. McLeod, R. and Schell, G. (2001) Management Information Systems. Prentice Hall, Upper Saddle River, NJ.

26. Mistry, J. J. (2005). A conceptual framework for the role of government in bridging the digital divide, Journal of Global Information Technology Management, 8 (3), 28-46.

27. Naarmala, J. (2004). "Going Digital - Explaining Dimensions of eGovernment," www.ebrc.info/ pages C86FCC04-3314-4DF9-9AE2-138286 0CB17F.asp

28. Ramaswamy, M and Selian, A. (2007). e-Government in Transition Countries: Prospects and Challenges, Proceedings of the $40^{\text {th }}$ Hawaii International Conference on Information Systems, (10 pages).

29. Scholl, H. J. (2003) "E-Government: A Special Case of ICT-enabled Business Process Change," Proceedings of the $36^{\text {th }}$ Hawaii International Conference on System Sciences, (12 pages).

30. Smith, M. L., et al. (2010) "Automating the Public Sector and Organizing Accountabilities," Communications of the Association for Information Systems, Vol. 26, Article 1.

31. Stefes, Christoph. (2008) "Governance, The State, and Systematic Corruption: Armenia and Georgia in Comparison," Caucasia Review of International Affairs, Vol. 2, No. 2, pp. 73-83.

32. Wimmer, M. R. et al (2001) "Electronic Business Invading the Public Sector: Considerations on Change and Design" Proceedings of the $34^{\text {th }}$ Hawaii International Conference on System Sciences, (10 pages).

33. Zmud, R. W. (1978) "An Empirical Investigation of the Dimensionality of the Concept of Information," Decision Sciences (9), pp. 187-195. 